\title{
La presencia del exilio republicano español en la Universidad Michoacana (1938-1966)
}

\author{
Verónica Oikión Solano \\ https://orcid.org/oooo-0oo3-4288-9541 \\ El Colegio de Michoacán, A.C., México \\ voikion@colmich.edu.mx
}

Gerardo Sánchez Díaz, La presencia del exilio republicano español en la Universidad Michoacana (1938-1966), Madrid, Universidad Michoacana de San Nicolás de Hidalgo/Marcial Pons, 2020, 608 pp., cuadros, ils. (Historia Contemporánea de América). ISBN: 978-84-1381-014-O

No cabe duda de que el oficio hace al maestro. La erudición intelectual del doctor Gerardo Sánchez Díaz se aprecia en esta obra portentosa de más de seiscientas páginas, que se ha sumergido en las entrañas de una problemática historiográfica de la que aparentemente se había dicho todo (debido a la voluminosa bibliografía disponible): el exilio español en tierras mexicanas. El libro cumple con creces el objetivo de dar luz sobre los mentores que en su periplo exiliar tocaron suelo michoacano y se asentaron en Morelia durante algunos años - preponderantemente entre fines de los treinta y hasta los sesenta- para reavivar y alentar la vida académica de la Universidad Michoacana de San Nicolás de Hidalgo.

La obra está dividida en dos bloques. La Primera Parte titulada "Los profesores del exilio republicano español en la Universidad Michoacana”, y la Segunda, denominada "El exilio español y la Universidad de Primavera Vasco de

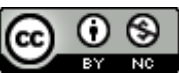

4.0 Internacional

Secuencia. Reseñas, 2021

http://secuencia.mora.edu.mx
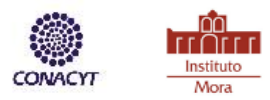


\section{Verónica Oikión Solano}

Quiroga”. Esta secuencia lógica ampara la estructura de su contenido, que se vertebra con las semblanzas de una cuarentena de intelectuales, escritores, educadores, pedagogos, psicólogos, juristas, diplomáticos, poetas, críticos literarios, filósofos, historiadores, sociólogos, biólogos, químicos, psiquiatras, médicos, agrónomos, artistas visuales, etcétera.

A manera de apartados introductorios, en la Primera Parte se realiza una apretada síntesis del contexto de la historia de España para ubicar a las y los lectores en el periodo de la Segunda República (1931-1939) y en la Guerra Civil (1936-1939). Esta última conllevó la "Diáspora y exilio", sucesos trágicos a los que se refiere el autor para en seguida pasar a explicar cómo fue puesta en marcha la "Operación Inteligencia”. Una logística original y nunca vista en el panorama del derecho de asilo internacional con la cual el gobierno mexicano trajo a buen puerto a cientos de republicanos, representantes de lo mejor de la inteligencia española, ${ }^{1}$ dándoles cobijo, protección y condiciones laborales para su integración en organismos e instituciones federales y en centros universitarios de la capital del país, sobre todo en la Universidad Nacional y el Instituto Politécnico. Lo que además redundó en el feliz establecimiento de la Casa de España en México, seguidamente convertida en El Colegio de México en 1940.

En universidades de la provincia mexicana (Puebla, Guadalajara, Guanajuato, San Luis Potosí, Monterrey), se diseminaron también varias de las mentes brillantes españolas, destacándose su arribo, estancia y permanencia en la Universidad

\footnotetext{
${ }^{1}$ Dolores Pla (1999, pp. 163-172) consideró que, de un total de 20 mil republicanos exiliados, $48 \%$ se adscribía al sector terciario, sobresaliendo profesionales de la cultura y docentes. Agrega además que posiblemente 692 exiliados tenían en su haber conocimientos especializados para la docencia y la educación. Y un número de 192 era el núcleo más competitivo académicamente y en donde se situaba lo más granado de la ciencia y la cultura española. 


\section{Verónica Oikión Solano}

Michoacana de San Nicolás de Hidalgo, ya fuese en calidad de profesores extraordinarios, o aquéllos con carácter para realizar estancias cortas con el fin de impartir cursillos; también los que tuvieron la categoría de planta, así como los conferencistas. Si bien Gerardo Sánchez apunta en su Introducción que: "poco o casi nada, se conoce acerca de la presencia de los exiliados en las instituciones educativas de los estados" (p. 10), hubiese sido conveniente haber subrayado más este desbalance historiográfico, justo para centrar la relevancia y la originalidad argumental de su obra.

La Primera Parte del volumen cuenta en su cierre con dos secciones que le ofrecen al lector un manto de alivio al escuchar "La voz y el canto de los poetas del exilio", y "La voz de los poetas solidarios con la causa republicana". Voces todas que en distintos momentos deambularon por la antigua Valladolid. Por sus callejuelas transitaron el clamor y la algarabía de Rafael Alberti, León Felipe, José Moreno Villa, Juan Gil-Albert, Pedro Garfias, Luis Cernuda, Juan Marinello, Porfirio Barba Jacob y Pablo Neruda.

El segundo bloque del libro tiene como contexto antecedente dos elementos: la integración del núcleo intelectual y cultural de Vanguardia Nicolaita, creada a instancias de los ex rectores Enrique Arreguín Vélez y Jesús Díaz Barriga, con el objetivo de impulsar el nicolaicismo y promocionar académicamente a la Universidad Michoacana. Y el muy relevante festejo por el IV Centenario del Colegio de San Nicolás, con su despliegue de eventos y publicaciones de repercusión nacional e internacional, y con la presencia notable del presidente Cárdenas en el acto central conmemorativo el 8 de mayo de 1940. 


\section{Verónica Oikión Solano}

Enseguida, el autor se concentra en los ciclos de la Universidad de Primavera Vasco de Quiroga con el apuntalamiento certero de quienes fueron sus protagonistas docentes, muchos de ellos del conglomerado exiliar español. La Universidad de Primavera (a semejanza de la Universidad Internacional de Verano, en Santander, España) representó un proyecto cultural y científico de gran relevancia por su originalidad en el medio académico nacional de la época. La Universidad Michoacana, a pesar de sus recursos limitados, entendió a la Universidad de Primavera como un primer peldaño en el establecimiento de una reforma universitaria que diera solidez a su ideario socioeducativo y pedagógico con un matiz modernizador (sobre todo con el rectorado de Victoriano Anguiano Equihua, 19401943) para abrirse hacia las vanguardias científicas y ser parte de los centros académicos internacionales, que, en ese periodo, se volcaban, predominantemente, hacia un humanismo científico y pacifista en medio del fragor del conflicto bélico mundial.

En toda esta historia poliédrica que nos ofrece el autor, por supuesto afloran la sagacidad en sus convicciones, la praxis activa y el liderazgo intelectual y diplomático de dos egregios mexicanos: Daniel Cosío Villegas y Alfonso Reyes, dejando ver sus sociabilidades impresionantes y el entramado de sus redes intelectuales, académicas y políticas bien establecidas en México y en el resto del mundo, y que lograron en conjunción la obra titánica del traslado exiliar y su ubicación laboral -en el caso de la Universidad Michoacana por los convenios establecidos con La Casa de España-, bajo el mando soberanista del presidente Cárdenas. El estadista mexicano dispuso que se abrieran las puertas a miles de 


\section{Verónica Oikión Solano}

españolas y españoles que habían sido el alma fértil, industriosa y productiva, así como el espíritu nutriente, cultural, académico y científico de la España republicana.

México reivindicó su autodeterminación y su derecho de ofrecer a los vencidos una mano amiga que los trasplantó al territorio nacional, y los transformó a muchos de ellos, siendo españoles por nacimiento, en mexicanos de corazón, pues en numerosos casos sus vidas y sus vivencias se asimilaron del todo convirtiéndose en mexicanas. No fueron pocos los que trajeron a cuestas su España invertebrada, y con ella a sus entrañables familias en medio de la tragedia a causa de la guerra, la derrota de las fuerzas republicanas y el triunfo del fascismo, y con un sinnúmero de sufrimientos, obstáculos y peripecias. En contraste, y de manera afortunada muchos de esos núcleos familiares se arraigaron y echaron raíces para asimilarse a la cultura mexicana.

\section{La presencia del exilio republicano español en la Universidad Michoacana} es una historia doliente intelectual narrada con una expresión emotiva por parte de su autor. El resultado es un mirador inquisitivo del encuentro de múltiples vidas vividas en una coyuntura excepcional que le dio un matiz de renacimiento a la ciencia y la cultura michoacanas. Por tanto, esta obra nos ofrece distintos planos que se van traslapando para mostrar una urdimbre local y a la vez muy compleja en sus acentos nacionales y transnacionales para explicarnos de qué manera, con qué elementos, y, sobre todo, con qué ánimos esperanzados llegaron los profesores e intelectuales transterrados $^{2}$ a la capital michoacana. Muchos de ellos reconocieron que Morelia

\footnotetext{
${ }^{2}$ El término transterrado fue concebido por el célebre filósofo José Gaos con la idea de plasmar la condición humana de miles de sus conciudadanos españoles, trasplantados, replantados o trasladados a México -como una segunda patria de destino- desde su patria de origen. El concepto fue bien recibido y se utiliza para caracterizar a la fuerte ola inmigrante española obligada a desplazarse a México a causa de la guerra civil y la instauración de la dictadura franquista.

E-ISSN 2395-8464

https://doi.org/10.18234/secuencia.v0i0.1976
} 


\section{Verónica Oikión Solano}

era una ciudad propicia para el estudio y el recogimiento. Y sus familias, esposas, hijas e hijos también se incorporaron al ritmo plácido de la urbe y acabaron por integrarse como parte de su gente y de la vida universitaria.

El libro trasluce en sus páginas el gesto solidario que engrandeció a las autoridades, a la planta académica y al estudiantado de la Casa de Hidalgo, incluso en medio de los desencuentros políticos e ideológicos que documenta el autor, y que en distintos momentos afectaron a los propios recién llegados. Sánchez Díaz rescata de forma erudita la disposición, la humildad, la entrega que mayoritariamente mostró el núcleo científico e intelectual español al incorporarse como profesores, conferenciantes y disertadores en las aulas del Colegio de San Nicolás y en los cuerpos académicos de las distintas escuelas y facultades de la propia Universidad. La impronta artística y científica introducida por los profesores españoles exiliados en los proyectos académicos nicolaitas, es uno de los aportes relevantes de este volumen.

No puedo dejar de enlistar a algunos de estos grandes catedráticos, conferencistas y educadores españoles que con tanta enjundia ha documentado el autor de esta obra: María Zambrano, Diego Rosado de la Espada, Fernando y Rafael de Buen Lozano, Juan y Joaquín Xirau Palau, Alfonso Rodríguez Aldave, Juan López Durá, Adolfo Sánchez Vázquez, Juan David García Bacca, José Peinado Altable, Cesar García Lombardía, Francisco Sanz Casabona, Juan Rejano, José Gaos, Fernando de los Ríos Urruti, Carlos Velo, José Giral, Pedro Carrasco, Gonzalo Rodríguez Lafora, Luis Recaséns Siches, José Medina Echavarría, Enrique DíezCanedo y Juan de la Encina, entre otros muchos más. 


\section{Verónica Oikión Solano}

Emprender la escritura de este libro significó para Gerardo Sánchez Díaz muchos años de investigación. La carga de fuentes consultadas (documentales -la fuente epistolar localizada es impresionante-, hemerográficas, testimoniales manuscritas y mecanoescritas, y bibliográficas) es extraordinaria y a la vez refinada y meticulosa, pues debió rastrear numerosas referencias en México, en España y en otros países europeos y en Estados Unidos. Incluso en fuentes de otros países latinoamericanos y hasta en acervos tan lejanos como los de Australia.

Además, la obra contiene un gran plus debido a la integración de un trabajo iconográfico notable y original. Esta es una labor de rescate que se debe valorar altamente. Todas las semblanzas cuentan con su respectiva imagen que le da un rostro al nombre del profesor exiliado. Incluye también numerosas imágenes que ilustran a lo largo del texto distintos eventos, personajes y momentos del acontecer académico nicolaita (reuniones, actos conmemorativos, recitales, trabajo de campo, etcétera). Este libro nos permite conocer las figuras académicas españolas que transitaron por las aulas de la Universidad Michoacana, introducirnos en sus propias vidas y en sus emociones y sus sentimientos, y, desde luego en su acción educativa y científica cotidiana, traducida en su docencia renovadora y en sus publicaciones académicas, literarias y ensayísticas. Sánchez Díaz se dio a la tarea de compilar en las semblanzas biográficas las obras producidas por las plumas de cada uno de los exiliados. Todo ese bagaje científico y cultural fue puesto a disposición de un estudiantado que, en su mayoría, se entusiasmó al abrírsele las puertas del conocimiento universal del arte y la ciencia.

Por ende, esta obra, al reunir por primera vez tantas y tan valiosas fuentes, también es muestra del rescate de una memoria histórica que debe preservarse para 


\section{Verónica Oikión Solano}

que no caiga en el olvido la fuerza del conocimiento de las disciplinas humanísticas y de las teorías científicas, impulsada por la renovación que supuso la cátedra del exilio español en la Universidad Michoacana.

Antes de finalizar quisiera verter mis puntos de vista críticos. En primer término, el volumen podría haber cerrado con unas reflexiones de parte del autor pues el libro no cuenta con conclusiones o consideraciones finales- para presentar un balance de la original aportación que representó para la Universidad Michoacana el ejercicio docente y de investigación de los académicos exiliados españoles. Sobre todo para destacar cuáles fueron las directivas universitarias y la política federal de integración de estos exiliados que dieron sus mejores frutos para la propia Universidad. Y, al mismo tiempo, para subrayar las limitaciones en algunos planes y proyectos académicos que no lograron concretarse del todo o se vieron frustrados o hasta cancelados por falta de recursos económicos o por distintos motivos políticos, como el conflicto universitario de 1943, que afectaron a la propia Universidad.

En este tenor hubiese sido revelador el tratamiento que se le diese con carácter de género a la corta estadía de la notable filósofa María Zambrano en el Colegio de San Nicolás (abril-diciembre de 1939). Zambrano fue la única mujer en el abultado grupo profesional español que llegó a la Universidad Michoacana. Cuestión relevante que no subraya el autor (cuya condición expresa meridianamente las limitaciones de las mujeres en el plano académico). Tampoco se aporta una valoración sobre las decisiones que tomó don Daniel Cosío Villegas - con una carga de cultura patriarcalal no permitirle a Zambrano expresar su deseo de permanecer en la Ciudad de México y enviarla a su llegada directamente a Morelia. En la capital michoacana, ella y su esposo -el historiador Alfonso Rodríguez Aldave- se sintieron bastante aislados 


\section{Verónica Oikión Solano}

intelectualmente, y dice mucho de la subestimación y menosprecio con que fue tratada por el hecho de ser mujer. El propio rector Natalio Vázquez Pallares, -con una actitud autoritaria, y creyendo erróneamente que ella era militante comunista-, le exigió ceñirse al dogma marxista, pues recién se había establecido que la Universidad propugnaría por el ideario socialista. Todo ello a la postre redundó en sus padecimientos orgánicos, y, finalmente, en la forzada separación de su trabajo docente, pues de manera atrabiliaria se le suspendió su cátedra en San Nicolás (páginas 67-85).

Finalmente, tengo la convicción, que transmito a las y los lectores, de que $L a$ presencia del exilio republicano español en la Universidad Michoacana (19381966) explora, con talento y erudición, en el pasado de una comunidad académica -

pero a la vez emocional por toda la tragedia vivida- que fue trasplantada a México con destino final a la ciudad de Morelia y a las aulas nicolaitas. A partir de ahora, la historiografía del exilio español cuenta con una obra indispensable para comprender la huella indeleble dejada por la estancia exiliar española en la Universidad Michoacana de San Nicolás de Hidalgo.

Referencias

Pla, D. (1999). Els exiliats catalans: un estudio de la emigración republicana española en México. México: INAH/Orfeó Catalá de Mèxic. 